\title{
Overcoming Institutional and Capability Barriers to Smart Services
}

\author{
Pekka Töytäri \\ Aalto University \\ pekka.toytari@aalto.fi \\ Ville Eloranta \\ Aalto University \\ ville.eloranta@aalto.fi
}

\author{
Taija Turunen \\ Aalto University \\ taija.turunen@aalto.fi \\ Sebastian Biehl \\ University of St.Gallen \\ Sebastian.biehl@unisg.ch
}

\author{
Maximilian Klein \\ University of St.Gallen \\ maximilian.klein@unisg.ch \\ Risto Rajala \\ Aalto University \\ risto.rajala@aalto.fi
}

\begin{abstract}
Smart services have potential to improve value creation and profitability of industrial firms and their customers. Defined as services that go beyond the upkeep and upgrades, traditionally bundled with products and helping companies to build intelligencethat is, awareness and connectivity. Combined with digitalization, services have had a major role in improving efficiency of existing offering and enabling new channels for service delivery.

Implementing the change toward smart services is challenging. Research shows that especially industrial companies maintain institutionalized beliefs and attitudes impeding the transformation, lack capabilities and resources for implementation, and face industrywide norms and relationship practices resisting the change.

The study explores the barriers in adopting smart services and is implemented as a multi-case study among six globally operating industrial companies. Our findings indicate classification of internal barriers, capability gaps, and external barriers, contributing a framework that describes the interplay between institutional forces and capability development in organizational change.
\end{abstract}

\section{Introduction}

Smart industrial services [1], [2] are services that are enabled and influenced by information that different industrial devices and processes generate, store and transmit to enable efficient operation, optimization, analysis and integration of business functions. Industrial services in general are often classified into categories of maintaining (product) functionality, ensuring operational availability, maintaining and improving performance, integrating processes, and operating production [3]. Each of these categories is affected by digitalization [4].

While research has studied the service transformation of industrial companies, few studies have explored the impact of digitalization of industrial services and moreover the institutional and organizational barriers that might complicate the comprehensive change. To fill the gap, this study explores the barriers to the development, launch, and implementation of smart services within manufacturing organizations. To address our research objective, we conducted a qualitative multi-case study among six globally operating industrial companies, which have already made significant investments in smart service development. The study was conducted as interviews in different industrial sectors. The findings identify three levels of barriers to the industry-wide adoption of smart services. The findings also suggest strategies for firms to overcome the barriers. The analysis illustrates the interplay between institutional inertia and dynamic capabilities during unfolding of the change. Further, our results suggest ways and approaches for managers to overcome the institutional and capability barriers.

\section{Theoretical Background}

\subsection{Barriers to change}

Overtime, organizations build culture, identity, and beliefs, which generally improve exploitation in stable market conditions. Thornton et al [5] define institutional logic as socially constructed sets of material practices, assumptions, values, and beliefs that shape cognition and behavior. The rules, norms, and beliefs surrounding economic activity define of enforce socially acceptable economic behavior [6]. Institutional logics serve as the interpretation schema for organizational actors, guiding their beliefs, attitudes, decisions, and actions [7]. The institutional logics include norms and values at the individual level, organizational culture and politics at the organizational level, and regulation and industry-side norms at organizational level [6]. Institutions are products of shared understanding of acceptable norms of activity [8]. A change in the logic depends on the endorsement of the new scheme of reasoning by the stakeholders involved in the exchange [9], [10]. In the case of smart services, the change requires a new identity supporting the new business logic involving smart services.

Institutional literature argues that organizational fields are organized by a dominant logic [9], and institutional change is effectuated by a change in this dominant logic. Institutional change is viewed as a transition from one dominant logic to another [12]. Smart services fundamentally change the nature of customer-supplier relationships by often re-defining firm boundaries, introducing availability and performance-based agreements, performance-based pricing, and re-organizing firms' resource and capability base. Each of these changes potentially re- 
brands the identity of the firm and shakes their power position toward the other business ecosystem members. Hence, successful implementation of smart services requires internal (organizational) and external (organizational fields') adoption of new institutional logic.

\subsection{Overcoming institutional barriers}

A change of logic requires acceptance of the new scheme of reasoning by the stakeholders [8], [9]. In the case of smart services, such an endorsement requires the perceived legitimacy of the new types of services by the key stakeholders in both the customer and supplier organizations. Suchman [10] defines legitimacy as the generalized perception or assumption that the actions of an entity are desirable, proper, or appropriate within some socially constructed system of norms, values, beliefs, and definitions. Pragmatic legitimacy is based on the self-interested calculation of an actor about the benefit or expected value of an activity on the expected performance of the evaluator. An organization may evaluate the legitimacy of smart services on the basis of the value created for the service provider. Conversely, moral legitimacy reflects a normative evaluation of the activities or the organization at large, whether or not the activity is considered to be "the right thing to do", and in line with the identity of the organization. This involves acknowledging the benefits of the logic for all actors involved. In smart services the moral legitimacy can be defined by the given service strategy. The cognitivecultural legitimacy depends upon the acceptance of the logic, based on what is considered desirable by the actors' involved and other connected stakeholders that may influence their evaluations. So in essence how well does the given actor network follow the strategy set for the smart services? To deal with these above listed institutional barriers, the institutional change literature suggests sensemaking and sensegiving as key mechanisms for facilitating the transformation [11]. Sensemaking refers to the meanings managers and employees construct during the attempted change of the offering portfolio, and the ways it is understood that the changes will affect the goals. Sensegiving on the other hand is a related process by which individuals attempt to influence the sensemaking of others toward a preferred redefinition of the reality [11]. Based on the research about legitimizing new schemes of interpretation in decision-making, we suggest that both organizational sensemaking and sensegiving play a key role in the introduction of the smart services within firms and organizational fields.

\subsection{Renewing the resource and capability base of a firm}

Organizations employ dynamic capabilities [12] to maintain and improve the match with market demands, as well as the operational capabilities to produce high quality products and services. Dynamic capability is defined as an organization's capacity to create, modify, and extend its resource and capability base [12]. Two different parameters for measuring the effectiveness of dynamic capabilities are suggested, being the evolutionary- and technical fitness [12].

Evolutionary fitness denotes and measures organizations' external fit with market demands and opportunities [12], [13]. Organizations that have high evolutionary fitness quickly adapt to emerging market opportunities or effectuate opportunities by creating and influencing market needs, or both. Evolutionary fitness is achieved by customer and market insight, learning, innovation, and successful introduction of new products and services that capture the emerging market opportunities. High evolutionary fitness may provide at least a temporary competitive advantage [14] unless other dynamic companies are equally quick to adapt. Previous literature has identified key capabilities and practices that support developing the evolutionary fitness. Launching novel services require careful customer selection, capabilities to gain customer insight by value research [15], [16], formulating the findings as value propositions [17], quantifying and convincingly communicating the value propositions, ability to engage and co-create value, verify and share the value created [18], [19], and leverage the outcome to effectuate an internal and external cultural change [20].

Companies may try to improve their evolutionary fitness either by adapting to current and predicted market demands, or by influencing the market demands in their favor [12]. Successful introduction of smart services may require both approaches. Value research driven discovery of new service opportunities or a broader market foresight analysis supports systematic development of likely valuable smart services, but a wider market success requires active influencing of the other business network members to increase the pressure on them to achieve the change in their institutional logic and resource and capability base.

Technical fitness [12], [13] denotes and measures the quality of the (novel) products and services. Technical fitness affects evolutionary fitness. Companies may be quick to anticipate and/or create market demand, but the products and services created to service the demand may not meet customer expectations, or the required quality may be too expensive to achieve. Competitiveness then is the product of both - the evolutionary fitness and the technical fitness. Clearly an organization may excel in both, either, or neither of the fitness categories. Inward focused companies may excel in technical fitness, but end up offering high quality products and services, which the markets or consumers do not need. On the other hand an innovative and market-focused company may succeed in anticipating and responding to emerging market needs, but fail to create offerings that meet customer's requirements. Long-term success requires both.

\section{Methodology}


Our research was conducted as a multi-case study among six prominent, globally operating European industrial and technology companies. We investigated the unfolding of smart services development and rollout within its real-life context. The phenomenon qualifies as contemporary and evolving, hence justifying the exploratory approach chosen [21]. The multi-case approach provided analytical benefits over a single-case by enabling comparison and contrast of the results to find the distinction of case specific findings and the more general phenomena.

\subsection{Context of the study and case selection}

Industrial companies are expanding their scope of business by service transformation [22], expanding their offering from products to services and solutions, building the required resources and capabilities, and organizing accordingly. The drivers behind the strategic move include commoditization of the existing business, and promising future service business opportunities in forms of sustainable relationships enabled by the service offering. The transformation is not new, Fang et al [23] found that on average the share of service revenue rose from $8,9 \%$ in 1990 to $42,2 \%$ in 2005 among manufacturing companies.

All the case companies in our sample are multinational companies. The case companies operate in different industrial sectors and provide a wide range of products and services to their customers with varying degrees of service orientation. Studied industrial fields include transportation systems, measurement engineering, machine industry, agricultural engineering, building infrastructure, and industry automation. The wide range of industries provides valuable insights on smart service transformation in different contexts. The case companies were selected based on purposive sampling [21]; all the case companies have been implementing smart services. However, it was our aim to select companies that were in different maturity phases in their service transformation journey so that we could identify the barriers that were proven to be able to overcome as well as those that seemed to be only context specific and unique for given firm. The details of these case companies are described in Table 1.

Table 1. Case company descriptions

\begin{tabular}{|c|c|c|c|c|}
\hline Firm & Industry & Sales & Staff & Smart service offering \\
\hline Alpha & $\begin{array}{l}\text { Transportation } \\
\text { systems }\end{array}$ & $\begin{array}{l}>7 \\
000\end{array}$ & $>25$ & $\begin{array}{l}\text { Commissioning, remote training, remote data transfer and handling, data } \\
\text { warehousing. Visualization of data, data evaluation, remote condition } \\
\text { diagnostics, performance contracting. }\end{array}$ \\
\hline Beta & $\begin{array}{l}\text { Measurement } \\
\text { Engineering }\end{array}$ & $>350$ & $>2$ & Commissioning, remote training, remote system upgrades. \\
\hline Gamma & Machine Industry & $\begin{array}{l}>2 \\
400\end{array}$ & $>15$ & $\begin{array}{l}\text { Service platform, commissioning, remote data transfer, remote system } \\
\text { upgrades, data evaluation, remote condition diagnostics, predictive } \\
\text { services, performance contracting, data based benchmarking, data based } \\
\text { consulting services. }\end{array}$ \\
\hline Delta & $\begin{array}{l}\text { Agricultural } \\
\text { engineering }\end{array}$ & $\begin{array}{l}>3 \\
600\end{array}$ & $>60$ & $\begin{array}{l}\text { Service platform, commissioning, remote training, remote data transfer, } \\
\text { data warehousing, remote system upgrades, data visualization, data } \\
\text { evaluation, automated data evaluation, remote condition diagnostics, } \\
\text { predictive services, performance contracting, managed services, data } \\
\text { based benchmarking, data based consulting services. }\end{array}$ \\
\hline Epsilon & $\begin{array}{l}\text { Building } \\
\text { infrastructure }\end{array}$ & $\begin{array}{l}>9 \\
000\end{array}$ & $>50$ & $\begin{array}{l}\text { Service platform, remote data transfer, visualization of data, data } \\
\text { evaluation, automated data evaluation, remote condition diagnostics, } \\
\text { predictive services. }\end{array}$ \\
\hline Zeta & $\begin{array}{l}\text { Industrial products } \\
\text { and services }\end{array}$ & $\begin{array}{l}>6 \\
000\end{array}$ & $>40$ & $\begin{array}{l}\text { IT hardware, software, and services; also advanced services, e.g. managed } \\
\text { services for own and 3rd party hardware. }\end{array}$ \\
\hline
\end{tabular}

\subsection{Data collection}

The empirical data of this study consists of in-depth interviews with experienced senior managers in our case organizations. The interviews were carried out between January and June 2016, and each interview was between 40 to 100 minutes of length. The sample size matches the recommendations for exploratory research [28]. To enable the relaxed communication the informants' anonymity was guaranteed through the assurance that the results would be released without any identifying information. It was perceived that anonymity encourages more candid discussion about successes and failures. Each interview was recorded and then transcribed verbatim. Following purposive sampling [21], the interviewees were chosen based on their role and experience, thereby most of them were sales, product, and service managers. To avoid single respondent bias, three or more managers were interviewed at each firm.

After selecting the case companies and informants, semi-structured interviews with predefined themes were conducted; interview contents were continuously adapted on the basis of previous interviews [24]. The interviews consisted of open-ended questions, initially 
crafted based on the literature review, and then modified and adjusted during the research process. All interviews were conducted face-to-face, and the transcribed data obtained from interviews was analyzed continuously during the research process. This was done in order to include or exclude the pre-defined themes that didn't seem to resonate with our initial interview structure. Furthermore, after each interview, the analysis of the interview was emailed to the informant by email. The informant was invited to correct any misunderstandings and add any information that that he or she had forgot to mention during the interview.

As case studies often apply abductive reasoning, our research process followed this paradigm, combining both inductive and deductive reasoning [25], [26]. Our study design involved simultaneous data collection and theory development, emphasizing an active interplay between theory and empirical evidence by going back and forth between the framework, data sources, and analysis [25]. Thus the objective of our approach was to match theory and reality in a nonlinear, path-dependent combination of empirical observations and theory. Hence, the research process of this study unfolded as an iterative process, characterized by the constant revision of the data collected, aiming to categorize the data according to the framework, which was initially derived from the literature and continuously adapted in the course of the research.

The primary analysis technique used was cross-case synthesis, aggregating the findings of each case through a cross-case analysis, and involving a careful comparison of the findings from each case [27]. Thus, the similar themes across the cases, the differences among the cases, and the reasons for those differences were analyzed, resulting in the identification of the common themes that were perceived to be relevant in this study.

\subsection{Data analysis}

Our data analysis followed an abductive analysis process, where the understanding of the phenomenon based on the literature laid the foundation for early interviews, which then used evolving themes to track important issues as the interviews progressed and our understanding of smart services in the real-life setting increased [25]. In practice, prior literature informed us about the generic barriers relating to novel services [22], and the interviews explored how these or other emerging barriers were manifested in the case companies. While prior literature guided the initial analysis, we did not employ preconceived codes, but relied on open coding, which used in-vivo labeling, and described the emerging concepts based on the actual language used by informants [28]. Specifically, we coded both tangible activities and practices, as well as more intangible beliefs, assumptions, and attitudes that were considered to affect smart services, in order to be as inclusive as possible in gaining a rich understanding of the topic.

Our data analysis started from the early observations [29], enabling us to structure our data into consistent blocks that reflect the emerging patterns in the data. This led to the identification of three categories of barriers, relating to the internally induced barriers, organizational capability gaps, and externally induced barriers to smart services. During the process we constantly revised our preliminary theory-based ideas of meaningful categories of data with empirically grounded insights of the barriers that impeded the adoption of smart services. We organized the data by using open and axial coding, and converting it to discrete thematic blocks that described the different types of barriers that the interviewed individuals experienced, the characteristics of each barrier, and the potential sense-making and sensegiving practices that managers used to overcome those barriers [28].

The analysis progressed through a highly iterative process, where the emerging findings were constantly reflected and revised between and within the research team and the informants at the case company. The research team held several interim meetings, and several managers from the case companies audited the preliminary results and provided feedback during the research. The frequent exposition of emergent results to both managerial (deep and local, context-specific knowledge) and academic (broad knowledge from several contexts) audiences ensured that we had reached sufficient understanding of the research phenomenon and captured the breadth and depth of how managers experienced the barriers in their own social reality [30], [31].

Because qualitative case research is sensitive to researchers' subjective interpretations, we used a variety of tactics to improve the quality of the research and the trustworthiness of the findings [21], [32], [33]. First, we used theoretical sampling and revelatory case logics to identify and gain access to empirical data that would provide theoretically and contextually rich insights in terms of the focal phenomenon. Second, we applied several forms of triangulation (theory, researcher, and data) to increase the credibility and validity of the study. In practice, we combined institutional and dynamic capabilities theories as our analytical lenses, used multiple researchers as cointerpreters, and drew empirical insights from several key informants, and different sources of data. Third, we conducted frequent member checks and peer debriefing to reduce researcher bias and increase the objectivity of the study. Finally, by providing a rich set of direct interview quotations to demonstrate interpretations, we support the transparency and conformability of the findings.

\section{4. $\quad$ Findings}

Our analysis identified sixteen barriers to adoption of the smart services, classified as internal barriers, 
capability gaps, and external barriers. The internal barriers resist change of mindset, beliefs, and identity [34]. The capability gaps represent the missing or weak capabilities and resources needed to successfully provide smart services i.e. meet the market requirements. Finally, the external barriers relate to the receptivity of the customers and the wider industrial network for the smart services and the changes in the relationship logic that the changes would bring about. The identified barriers are discussed next.

\subsection{Internal barriers}

Our analysis revealed three basic themes of internal barriers of which all reflects somehow the organizational culture and management principles. Services were seen to be very distinctive form the traditional, exploitative business and therefore the identity and legitimacy inhibited companies in their transition.

Management culture: Our analysis revealed that the existing management culture often favors and rewards short-term achievements of product-based offering. Smart services represent complicated and difficult-to-evaluate offerings, for which the salescycles are long and outcomes risky. We find that the management practices, goals and incentives reflect the prevailing product-focused culture, which firmly maintain the prevailing sales culture. The following quotes illustrate this finding.

Internal marketing of the new service was an issue: The service culture was not yet developed correctly. We were still stuck in the mentality of being a product company. (Beta).

In addition, service technicians have to be included in these new technologies through different wages, incentives. (Delta)

Identity: Many of the case companies have successful history and strong identity in their existing business. The customer-facing personnel identify themselves with the existing (mature and productdominated) offering portfolio.

Selling services is much different than selling products. ...We all (salespeople) are hired to sell products not services." (Zeta).

Our smart service business grew organically; we had no clear development process. Service just did not have a lot of status at that time. (Beta).

It was a challenge and a struggle to convince people of smart services - they are used to the predictable lifecycles of products. Smart services with long product life seem complicated in comparison. (Beta).

Legitimacy: Smart services often redefine the roles and responsibilities within the supplier companies, and expand the scope of the customer relationships. The new services are not a legitimate part of the offering portfolio or the relationship scope.

We are a mechanical engineering company with service, not a service business. The service developed over time. Because of this, the whole mindset is not service-driven, but product-driven. We do have this problem. (Gamma).

Dealers would simply refuse to bill customers for services they did not render at the customers' site. (Delta).
People resist [Smart Services] since they are something new, unknown. Something could happen, something could not work. [...] Hence the argument, I only act if something is truly broken. (Delta).

Maybe the change is also between the ears, that we would sell something else than the traditional. (Zeta).

People have to be won over. The internal need for discussions and marketing was much higher than expected and severely underestimated. (Delta).

Mindset problem. The mindset problem comes with a resource problem. We simply do not have enough Smart Talents. (Gamma)

\subsection{Capability gaps}

As noted above, the organizational barriers were not, however, limited only to the organizational culture and identity but reflected also novel capabilities that companies did not necessarily posses. The capability gaps were mainly related to the technical problems and level of communication between the stakeholders but also the reconfiguration problems towards service orientation were recognized.

Inability to provide smart services: Technical immaturity or outdated technology of the existing equipment fleet and incomplete support infrastructure are among the key reason preventing case companies from providing smart services.

Technical problems led to anxiety among our customers and service technicians. [...] The worry, that systems break down - no worry, that people fail, don't know what to do [...], but permanent worry about technology, that data gets lost, that something is disrupted, that something breaks down. (Delta).

When we started with Smart Services, we didn't have much to show. We only had few data and didn't know if we should wait until we had more substance [...] You enter this vicious cycle [where the dealers say]: , Well, but I can only talk with the customer when I have this and that feature. (Delta).

Access to influence: Generally, selling innovative new offerings requires access to influential and visionary decision makers, who are receptive to the benefits provided by the smart services. The existing business contacts of the case companies are often built to procurement units, which are not receptive to new ideas.

The idea is to use key account managers that actively address these issues with decision makers at the customers and try to launch the whole thing. It's definitely a challenge, because you have to make new connections to stakeholders. (Beta).

Governance infrastructure: The internal IT systems, management systems, incentives, and organizational structures are built overtime and optimized for the existing product-based businesses. The existing infrastructure has been built over time to serve the existing business logic. As the requirements of the smart services provision and the needed capabilities and practices are significantly different, the existing structures do not serve the emerging logic well. 
Roles and responsibilities should have been clearly defined much earlier. Initially, nobody knew who had what to coordinate. (Delta).

It's challenging in the product-oriented company where all the processes and systems support product-orientation. (Zeta).

In addition, service technicians have to be included in these new technologies through different wages, incentives. (Delta).

[When we started offering automated Smart Services] we had to define new processes. [...] We had to make rules that a ticket [initiated by a machine] gets treated the same way as if the customer had called himself. (Gamma).

Initially we focused too intensely on the technical solution. The whole application of Smart Services was put on a level with the machine can send data. The typical way of thinking was that if the machine can send data, the work is done - and people will automatically take care of the data, analyze it and know what to do. (Epsilon).

The only focus was the technical equipment that enabled the machine to send data. [...] Everything else was not considered - that you have to educate and inform people, that perhaps new tools are needed, that new processes are needed. That was all neglected. [...] This was surely the main reason that the earliest projects were never successful. (Epsilon)

Lack of resources: The case companies often lack the necessary financial resources to implement the infrastructure for smart services.

We only offer this [Smart Service] in markets, where we have the necessary downstream processes in our service organization well established. Nothing is more foolish than having a [predictive call] from a machine and no one acts on it. If this is the case, you lose more and faster than you can ever win. [...] The process includes the necessary resources you need to run it! If a market is too small, then we do not offer [Smart Services]. [...] I promise the customer a lot, if I cannot keep these promises I squander all trust. (Gamma).

We simply do not have enough Smart Talents, i.e. personnel qualified for Smart Services. This resource problem goes hand in hand with a usage problem. If I had more customers for Smart Services, I could afford more resources. At some point I have to make the decision whether we believe [in Smart Services], then I have to commit resources, even when I don't have any usage. (Gamma)

Insufficient information on installed base: The case companies often have a significant installed based, but seldom sufficient and applicable installed base information to efficiently leverage it.

Regarding complexity - what makes it [providing Smart Services] difficult for $u$ s is the long life cycle [of our products]. This makes it very difficult for us, this extreme diversity in the installed base. [...]. There is this huge number of components, where we cannot read out anything and do not even know what is installed at all. (Epsilon)

Cost-Benefit of installed base modernization: Many of the case companies have built their installed base over time, and need to maintain outdated equipment. In many cases the cost of upgrading the installed base to support the smart services is prohibitively high.

[Smart Services were pushed by the top management with the premise that no changes be necessary regarding organization, infrastructure, or additional technical equipment]. This had the disadvantage that we didn't cover the old machines in the installed base, since we needed a specific software status. Even where old machines could have been retrofitted we didn't do that. We made a cut. (Gamma)

High product life times have an impact on the duration of time you can do service for. Initially you have the challenge to connect your big, relatively old installed base - and to what cost! If you can only transmit essential signals you have to ask yourself the question whether they are enough to offer preemptive services. (Epsilon)

Unclear legal status of the information: Not surprisingly, the use of the industrial data represents significant challenges.

Data belongs to the customer. Software, however, is our intellectual property. (Delta)

Data that we receive from the customer is our property. However, we are under the obligation not to share the data with third parties. That's clear, that's an obligation. (Gamma)

Inability to build value propositions: As a prerequisite for value communication, the companies face challenges in actually understanding what is valuable for their customers and building value propositions accordingly. Effective value propositions address customer's timely business goals, and offer tangible evidence of value:

We had data but didn't really know what to do with it. You have to understand the customers' business, their pain. You have to connect an idea with this customer pain." (Delta).

The assumption that we know what to do and what the customer should do has failed. These things [Smart Services] have to be jointly developed. (Delta).

We are really struggling to develop a value proposition. This technology is just emerging, developing. (Delta)

Inability to communicate value: The existing customer relationships have been built around (physical) products and product innovations. The customer-facing staff lacks the confidence and capabilities to communicate value.

Our dealers cannot argument professionally. [...] They cannot conduct a professional sales pitch with arguments. They can all sell a [conventional product]. But I personally do not believe that they can sell one of todays' [products]. These include such advanced features you wouldn't believe it. (Delta).

Also, we have the status quo of today, and we know what comes in one year, but our sales people that talk to the customer, they rather want to talk about horsepower and kilowatts than these new technologies. (Delta).

Our dealers did not use the time to convey positive experiences to demonstrate value. (Delta)

\subsection{External barriers}

Industrial buying culture and relationships: Smart services represent a high-value offering with potential for improved profits for all stakeholders. Smart service provision also requires a significant upfront investment from the supplier company, hence requiring higher profitability to compensate for the investment. However, often the existing relationships and the prevailing industrial procurement culture favor short-term wins, exercise of high buyer-power, and 
cost-based pricing. The focus is on transactional efficiency and arms-length relationships. The value focus of the smart services is often not aligned with the price focus of the industrial buying.

It is difficult to get money from the customer for Smart Services. [...] In addition, many topics are so intermingled that you cannot always strictly separate them. [...] Because of this, we have miscellaneous products that overlap a bit. (Epsilon).

With an old family business in Europe, customer relationship is everything - personal contacting, personal guidance. They only see value when someone is there personally. He doesn't see value when someone he doesn't know does something with a computer and then sends a huge bill. (Delta).

Full-Service packages are mixed calculations. Costs arise when customers use the product until it is broken. With smart services, I can see problems before it breaks. To develop the business case and show value from reducing secondary damage, that is our job. (Delta)

Smart services generally require a long-term orientation to customer relationships and high levels of trust and openness.

There is this permanent fear to be liable to recourse, that someone takes customer's data. This fear is crippling. We do everything in our power to have legal security, to close all loopholes - and to tell everything that we know our customer. For instance, data does not go to the US. That simply won't work. (Delta).

Data security was a huge issue - so we trained our employees regarding the topic. We defined clear rules for each [smart service] session: The customer initiates it, and the customer ends it. [...] We obligated ourselves not to analyze any data, except the customer gives his express permission. This way we established trust. (Gamma).

Data security is the biggest issue in Germany and in Europe. We have found in many surveys that customers are highly critical regarding unrestricted access to their data. (Delta)

Reputation and brand image: For many of the case companies their existing brand as a product company, as well as the reputation as service provider represent a significant perceptional barrier to overcome.

We are perceived as a product company by our customers, less as a solution or service provider. (Beta)

Unwillingness to outsource: Service provision most of often involves change in the organizational boundaries: the customer outsources a business function to the supplier. Customers are often unwilling to give up resources and capabilities, fearing future loss of competitive advantage, unhealthy dependence, and similar consequences.

[Our customers] don't want to be dependent at the moment because they are afraid to lose capabilities to maintain and service their machines on their own. However, I think there will be change in the next couple of years due to cost pressure as well as rising complexity of systems that necessitate highly trained specialists. (Alpha)

Non-matching solution visions: Perhaps relating to the inability to build value propositions, customers and service suppliers often have deviating views on solution scope. What represents an undividable bundle of activities, capabilities and resources for a customer, may include undesirable demands for the service provider.

Customers have never told us what they expect. They only tell us when expectations haven't been met. - The customers are not communicating specific numbers because he is unaware of them. But inwardly he has expectations that are based on experiences that he had. (Delta).

The customer expects that our [Smart Services] are so capable software-wise, that the integration of all his different software systems works. Linking data to the customer in his way of expressing himself and for different systems is the biggest challenge, for this we need IT from external professionals. (Delta).

Preventive maintenance will lead to fewer direct contacts with the customer. [...] At some point, the customer will say, this is too expensive' - because he doesn't have any machinedown experiences any longer. (Delta).

Customer expectations are clear. If these cannot be met adequately with the current offering, we are deliberately nontransparent with our customers. Arising issues are avoided by offering all-in packages that transfer potential risks from customer to us. (Delta).

The Table 2 summarizes the internal barriers, resource and capability gaps, and external barriers to implementing smart services.

Table 2. Internal barriers, capability gaps, and external barriers to adoption of smart services

\begin{tabular}{|c|c|c|}
\hline $\begin{array}{l}\text { Internal } \\
\text { barriers }\end{array}$ & $\begin{array}{l}\text { Resource and } \\
\text { capability gaps }\end{array}$ & $\begin{array}{l}\text { External } \\
\text { barriers }\end{array}$ \\
\hline $\begin{array}{l}\text { Management } \\
\text { culture, } \\
\text { Identity, } \\
\text { Legitimacy }\end{array}$ & $\begin{array}{l}\text { Inability to provide } \\
\text { smart services, } \\
\text { Access to } \\
\text { influence, } \\
\text { Governance } \\
\text { infrastructure, Lack } \\
\text { of resources, } \\
\text { Insufficient } \\
\text { information on } \\
\text { installed base, } \\
\text { Cost-benefit of } \\
\text { installed base } \\
\text { modernization, } \\
\text { Unclear legal status } \\
\text { of the information, } \\
\text { Inability to build } \\
\text { value propositions, } \\
\text { Inability to } \\
\text { communicate value }\end{array}$ & $\begin{array}{l}\text { Industrial } \\
\text { buying culture } \\
\text { and } \\
\text { relationships, } \\
\text { Reputation and } \\
\text { brand image, } \\
\text { Unwillingness } \\
\text { to outsource, } \\
\text { Non-matching } \\
\text { solution visions }\end{array}$ \\
\hline
\end{tabular}

\section{Discussion}

Our study investigates the emerging smart service business offering among six cases. Industrial service providers are responding to the changing needs of customers and emerging market opportunities by overcoming internal barriers and building new capabilities. In order to understand which factors seem 
to inhibit the change we analyzed the change process in great detail. Our analysis identified three internal barriers, nine resource and capability gaps, and four external barriers to the adoption and implementation of smart services within the industry. Thus quantitatively, the biggest set of barriers seem to lie in the resources and capabilities and in more detail the lack of managerial cognition of reconfiguration and disengagement.

\subsection{Theoretical implications}

We build our analysis of the findings on the interplay between two organizational theories, the institutional logic [7] and dynamic capabilities [12], (see also [6]). First, within individual firms, the transformation requires change in the attitudes, beliefs, and norms that shape the business practices [34]. Gioia and Thomas [36] concluded that to induce change, the organization must be destabilized and convinced that there is a necessity for a different way of seeing and being. Drawing on the conceptualization of organizational and strategic change [37], this first stage of transformation is about "unfreezing" the current beliefs, attitudes, norms, and schemes of reasoning by managerial sensegiving. At this stage the processes should focus on motivating the need to change and communicating the new inspiring vision. Managers must create urgency for change. A rather common sensegiving strategy portrays the current (product) offering as becoming commoditized, leading to loss of competitiveness and low profitability. Then, from the capability perspective, our findings indicate that the case companies have deeply rooted routines and capabilities to effectively conduct their established business. Hence, the current (operational) capabilities and resources of the organizations likely feature high technical fitness, but deteriorating evolutionary fitness [12]. Agarval and Helfat [38] define strategic renewal of an organization to include the process of replacement of attributes of an organization that have the potential to substantially affect its long-term prospects. We conclude that managers may need to divest current operational capabilities and resources to create room for new operational capabilities with higher evolutionary fitness. Otherwise the firms would continue maintaining unprofitable technically fit routines, resources, and capabilities. Based on our findings, a salient example of the high technical but low evolutionary fitness is the sales function, which in many industrial companies have over time developed effective product sales practices, but which are becoming increasingly dysfunctional in meeting the new demands.

The next stage in strategic renewal is about building a shared vision and new capabilities, routines, and resources to implement the new vision. The new vision needs to motivate the desirability of new smart services among the organizational actors. The greatest challenge for the managers during the this stage is to mobilize the firm's dynamic capabilities to modify and extend its resource and capability base, and build entirely new resources and capabilities, to achieve evolutionary fitness. Our findings illustrate the magnitude of the challenge. Among many things, corporate training programs and incentive structures continue maintaining the established capabilities. Among the key capabilities to overcome the identified internal challenges is to align governance and incentives with the new vision, invest in value-based selling capabilities to build and communicate value [16], industrialize [19] the service provision, and segment to choose right customers for the smart services approach.

Finally, the third "refreezing" stage involves influencing and accelerating the institutional change of beliefs and accepted business models and relationships within the surrounding business ecosystem to create receptivity for the new relationship logic, and align the visions about what is proper and "right" way to conduct business in the industry. Smart services as novel offerings require convincing proof of customer value. Hence, smart services are frequently a part of a broader, value-based strategy. As an example sensegiving strategy, Zeta has a established a global function to promote value-based relationships in industry events, and produce whitepapers, seminars, books, industrial benchmarking studies, and quantified reference stories to influence industrial relationship practices. To gain profound understanding of their customers and market opportunities, the case companies study their customer's business processes and business drivers to identify and assess novel opportunities for value creation. Simultaneously, firms need to focus on internal exploitation efficiency and institutionalization of the new practices, resources, and (operational) capabilities to create a lasting impact. While the reconfiguration and development of new operational capabilities may have improved the evolutionary fitness of the firm, the technical fitness of the new capabilities and resources likely needs attention. The Table 3 summarizes our framework by explaining the different stages of transformation, as well as dividing the stages into institutional and capability related transformative actions.

Table 3. Stages of overcoming barriers to change.

\begin{tabular}{|l|l|}
\hline Unfreezing \\
\hline $\begin{array}{l}\text { Institutional } \\
\text { perspective }\end{array}$ & $\begin{array}{l}\text { Managerial sensegiving to create } \\
\text { urgency for change }\end{array}$ \\
\hline $\begin{array}{l}\text { Capability } \\
\text { perspective }\end{array}$ & $\begin{array}{l}\text { Divesting existing capabilities and } \\
\text { resources to enable adoption of } \\
\text { new capabilities and resources }\end{array}$ \\
\hline Building & $\begin{array}{l}\text { Managerial sensegiving for new } \\
\text { shared vision }\end{array}$ \\
\hline $\begin{array}{l}\text { Institutional } \\
\text { perspective }\end{array}$ & $\begin{array}{l}\text { Application of the firm's dynamic } \\
\text { capabilities to reconfigure and } \\
\text { renew the capability and resource } \\
\text { base }\end{array}$ \\
\hline Capability
\end{tabular}




\begin{tabular}{|l|l|}
\hline $\begin{array}{l}\text { Institutional } \\
\text { perspective }\end{array}$ & $\begin{array}{l}\text { Influencing industry-wide beliefs } \\
\text { and norms to build receptivity for } \\
\text { smart services }\end{array}$ \\
\hline $\begin{array}{l}\text { Capability } \\
\text { perspective }\end{array}$ & $\begin{array}{l}\text { Refining operational capabilities } \\
\text { for exploitation efficiency }\end{array}$ \\
\hline
\end{tabular}

\subsection{Managerial Implications}

Our findings illustrate the impact of digitalization on industrial services, and contribute to the discussion of digitalization of industrial operations, service transformation, and the interplay between institutional change and dynamic capabilities to achieve organizational change (Table 3 ).

For practicing managers the implications are rather straightforward: to achieve the potential of smart services, the managers need to engage in sensegiving to overcome the prevailing beliefs and rules, and prepare to renew the organizational capabilities and resources, focusing especially on the governance, incentives, and value-based capabilities, processes, and tools. It is also important to acknowledge, as our findings illustrate, that smart services are not just something to add on, but a part of a broader, paradigmatic change in industrial relationships and business models, and hence require simultaneous change in industrial beliefs, norms, and practices within the business ecosystem. Progressive companies need to effectuate the change within their network.

\section{References}

[1] H. Kagerman, J. Helbig, A. Hellinger, and W. Wahlster, "Recommendations for Implementing the Strategic Initiative INDUSTRIE 4.0: Securing the Future of German Manufacturing Industry; Final Report of the Industrie 4.0 Working Group.," 2013.

[2] G. Allmendinger and R. Lombreglia, "Four strategies for the age of smart services," Harv. Bus. Rev., vol. 83, no. 10, pp. 131-145, 2005.

[3] T. T. Turunen and M. Toivonen, "Organizing customeroriented service business in manufacturing," Oper. Manag. Res., vol. 4, no. 1-2, pp. 74-84, Jan. 2011.

[4] E. Brynjolfsson and A. McAfee, Brynjolfsson, E., \& McAfee, A. (2012). Race against the machine: How the digital revolution is accelerating innovation, driving productivity, and irreversibly transforming employment and the economy. Brynjolfsson and McAfee, 2012.

[5] P. H. Thornton, W. Ocacio, and M. Lounsbury, The institutional logics perspective: A new approach to culture, structure, and process. Oxford, UK: Oxford University Press, 2012.

[6] C. Oliver, "Sustainable competitive advantage: Combining institutional and resource-based views," Strateg. Manag. J., vol. 18, no. November 1996, pp. 697-713, 1997.

[7] P. H. Thornton, W. Ocasio, and M. Lounsbury, The Institutional Logics Perspective: A New Approach to Culture, Structure, and Process. Oxford, UK: Oxford University Press, 2012.
[8] R. Suddaby, K. D. Elsbach, R. Greenwood, J. W. Meyer, and T. B. Zilber, "Organizations and Their Institutional Environments - Bringing Meaning, Values, and Culture Back in: Introduction To the Special Research Forum," Acad. Manag. J., vol. 53, no. 6, pp. 1234-1240, 2010.

[9] T. Reay and C. R. Hinings, "Managing the Rivalry of Competing Institutional Logics," Organization Studies, vol. 30, no. 6. pp. 629-652, 2009.

[10] M. C. Suchman, "Managing legitimacy: Strategies and institutional approaches," Acad. Manag. Rev., vol. 20, no. 3, p. 571, Jul. 1995.

[11] D. A. Gioia and K. Chittipeddi, "Sensemaking and Sensegiving in Strategic Change Initiation," Strateg. Manag. J., vol. 12, no. 6, pp. 433-448, 1991.

[12] C. E. Helfat, S. Finkelstein, W. Mitchell, M. Peteraf, H. Singh, D. Teece, and S. G. Winter, Dynamic capabilities: Understanding strategic change in organizations. John Wiley \& Sons, 2009.

[13] D. J. Teece, "Explicating dynamic capabilities: The nature and microfoundations of (sustainable) enterprise performance," Strateg. Manag. J., vol. 28, pp. 1319-1350, 2007.

[14] S. L. Brown and K. M. Eisenhardt, Competing on the edge: Strategy as structured chaos. Harvard Business Press, 1998.

[15] L. A. Bettencourt and A. W. Ulwick, "The customercentered innovation map.," Harv. Bus. Rev., vol. 86, no. 5, pp. 109-14, 130, May 2008.

[16] R. Rajala, P. Töytäri, and T. Hervonen, "Assessing Customer-Perceived Value in Industrial Service Systems," Serv. Sci., vol. 7, no. 3, pp. 210-226, 2015.

[17] J. C. Anderson, J. A. Narus, and W. van Rossum, "Customer value propositions in business markets.," Harv. Bus. Rev., vol. 84, no. 3, pp. 1-10, Mar. 2006.

[18] P. Töytäri, R. Rajala, and T. Brashear Alejandro, "Organizational and institutional barriers to value-based pricing in industrial relationships," Ind. Mark. Manag., vol. 47, pp. 53-64, 2015.

[19] K. Storbacka, "A solution business model: Capabilities and management practices for integrated solutions," Ind. Mark. Manag., vol. 40, no. 5, pp. 699-711, Jul. 2011.

[20] A. Jalkala and R. T. Salminen, "Practices and functions of customer reference marketing - Leveraging customer references as marketing assets," Ind. Mark. Manag., vol. 39, no. 6, pp. 975-985, Aug. 2010.

[21] K. M. Eisenhardt and M. E. Graebner, "Theory Building from Cases: Opportunities and Challenges," Acad. Manag. J., vol. 50, no. 1, pp. 25-32, 2007.

[22] W. Ulaga and W. J. Reinartz, "Hybrid Offerings: How Manufacturing Firms Combine Goods and Services Successfully," J. Mark., vol. 75, no. 6, pp. 5-23, 2011.

[23] E. Fang, R. W. Palmatier, and J.-B. E. M. Steenkamp, "Effect of Service Transition Strategies on Firm Value," $J$. Mark., vol. 72, no. 5, pp. 1-14, 2008.

[24] D. Silverman, Interpreting qualitative data: Methods for analyzing talk, text and interaction. London: Sage Publications, 2012. 
[25] A. Dubois and L.-E. Gadde, "'Systematic combining'A decade later," J. Bus. Res., vol. 67, no. 6, pp. 1277-1284, 2014.

[26] G. Easton, "Critical realism in case study research," Ind. Mark. Manag., vol. 39, no. 1, pp. 118-128, Jan. 2010.

[27] R. K. Yin, Case Study Research: Design and Methods (Applied Social Research Methods), 5th editio. Thousand Oaks: Sage Publications, 2014.

[28] J. Corbin and A. L. Strauss, Basics of qualitative research: Techniques and procedures for developing grounded theory, 4th Editio. Newbury Park, CA: Sage Publications, 2015.

[29] E. Gummesson, Qualitative methods in management research, 2nd Editio. Thousand Oaks: Sage Publications, 2000.

[30] D. A. Gioia, "Give it Up!: Reflections on the Interpreted World (A Commentary on Meckler and Baillie)," J. Manag. Inq., vol. 12, no. 3, pp. 285-292, 2003.

[31] T. Järvensivu and J.-Å. Törnroos, "Case study research with moderate constructionism: Conceptualization and practical illustration," Ind. Mark. Manag., vol. 39, no. 1, pp. 100-108, Jan. 2010.

[32] M. Beverland and A. Lindgreen, "What makes a good case study? A positivist review of qualitative case research published in Industrial Marketing Management, 1971-2006," Ind. Mark. Manag., vol. 39, no. 1, pp. 56-63, Jan. 2010.

[33] Y. Lincoln and E. Guba, "Paradigmatic controversies, contradictions, and emerging confluences," in Handbook of qualitative research, 2000.

[34] W. R. Scott, Institutions and organizations: Ideas, interests, and identities. Sage Publications, 2013.

[35] P. H. Thornton and W. Ocasio, "Institutional Logics," in The SAGE Handbook of Organizational Institutionalism, London: Sage Publications, 2008.

[36] D. A. Gioia and J. B. Thomas, "Identity, image, and issue interpretation: Sensemaking during strategic change in academia," Adm. Sci. Q., vol. 41, pp. 370-403, 1996.

[37] K. Lewin, Field theory in social science. 1951.

[38] R. Agarwal and C. E. Helfat, "Strategic renewal of organizations," Organ. Sci., vol. 20, no. 2, pp. 281-293, 2009. 